\title{
The prescribing cascade- spotting and aborting it
}

\section{Dixit SM}

Sanjaya Mani Dixit, Assistant Professor; Department of Pharmacology, Kathmandu Medical College Teaching Hospital, Kathmandu, Nepal.

\begin{abstract}
A s a physician taking medication history at different times, you might certainly have come across long lists of medicines being taken by patients. This is especially true when you are seeing elderly patients. You listen to them in awe to the never ending list of medications and might frown a bit on the long list. But when you relate the medicines to the ailment and the symptoms they still might look relevant. You might even end up adding another one or two medicines for the new symptoms they have come across in recent days or weeks. But, how often do we question the absolute need of all the drugs the patient has been taking in total? Can the patient's body handle the side effects of all these medicines? Will adding another drug not add burden to the frail diseased body of the patient? Is it that the drugs are being added just to counteract the side effects of the drugs the patient is taking and that a new drug is not altogether necessary? Just reducing the dosing of the medicine prescribed earlier or giving a drug from a different class may help the condition of the patient? Is it about time that we understand the concept of prescribing cascade and work on it?
\end{abstract}

Prescribing cascade refers to inaccurately assessing the adverse drug reactions of drugs currently prescribed as signs and symptoms of a new condition, thereby resulting in prescription of a new medication. This may lead to newer side effects, drug interactions, newer symptoms and newer misdiagnoses. The concept of prescribing cascade was first given in 1995 in the Lancet ${ }^{1}$. Identifying and reducing prescription cascade is important and actionable opportunity to improve medication safety ${ }^{2}$. A few examples given below should help form a clear concept on prescription cascade. Anticholinergics (Oxybutynin) is prescribed for incontinence caused

DOI: https://doi.org/10.3126/jkmc.v8i4.32380

Address for correspondence

Mr. Sanjaya Mani Dixit

Assistant Professor; Department of Pharmacology

Kathmandu Medical College Teaching Hospital, Kathmandu, Nepal

E-mail: sanjayadixit@gmail.com

ORCID id: 0000-0003-2733-1785 by Cholinesterase inhibitor. Baclofen is prescribed for muscle pain caused by statins. Cough suppressants are often prescribed for cough precipitated by ACE inhibitor. Colchicine is prescribed for hyperuricemia caused by Thiazide diuretics. Levodopa/Carbidopa is prescribed for tremors caused by Paroxetine or Haloperidol ${ }^{2}$.

Prescribing cascade leads to polypharmacy. Polypharmacy is a common problem, more so in the elderly population ${ }^{3}$. The elderly patients have multiple co-morbidities, are frail and are on multiple drug therapies at the same time. They seem to have a never ending list of medications, except for frowning on the long list, not much is done. Though so, the concern always remains there, issues related to drug interactions, adverse drug reactions, patient's quality of life and prescription cascade. Since polypharmacy is a risk factor for adverse drug reactions (ADRs), reducing the prescription cascades could in turn reduce ADRs too ${ }^{3}$. Also, because the clinical trials of drugs are conducted in the youth population, rather than the elderly, the risk of ADR in elderly may be particularly high ${ }^{4}$. The clinical trials are conducted for a single medication and only identify the adverse effects associated with a single drug. So many ADRs are not observed in relatively small clinical trials 5 . They do not account for the multiple drugs that the patients can be taking at a particular time and thereby increased drug interactions with multiple drugs is a possibility.

Drug cascade usually occurs due to the involvement of multiple prescribers and a suboptimal review of the patient's medication history. The area of prescription cascade is too often neglected in medical practice, more so in a country like Nepal where patients visit different specialty doctors in different institutions. This gets more complicated with the patient not giving complete details regarding the medications that he/she is consuming or has consumed in recent times. For some reason the communication between the caregiver and the patient has not been ideal, leading to communication gaps and even miscommunication at times. Some patients even stop medication on their own without consulting their physician, ignoring the ill effects their action can cause 
on their ailment or its management. Yet another kind of patient keep on taking the drug for indefinite time, without appraising its need at current times.

In recent years, Nepal has seen a substantial increase in the non-communicable diseases (NCDs). With the increased incidence of chronic diseases like diabetes, hypertension and hyperlipidemia we are seeing a tremendous increase in the use of medications in the elderly people. Every specialist treats the patient in their specialized field and most of the times add medication for the condition identified. This way there is mere addition of drugs as deemed necessary by different specialists. However, little effort is made towards deprescribing the medications. Deprescribing medications may just be as important as prescribing medications for the patient. The process of deprescribing removes unwanted medication for the patient by assessing the clinical condition of the patient and also helps reduce inappropriate polypharmacy ${ }^{6}$. Sir William Osler is known to have quoted "The good physician treats the disease; the great physician treats the patient who has the disease ${ }^{7} . "$ So, duty of a physician is to treat the patient as a whole and not in various parts under specialist lenses.

To prevent this, physician should consider each new sign and symptom as a potential adverse effect of a drug, more so if dose of a drug was recently changed or an altogether new drug was recently prescribed for the patient. Also, adding a new drug to pharmacotherapy in an elderly patient should be done with extreme caution and drugs should be added only when they are deemed absolutely necessary and even in that case the drug should be started at the lowest possible dose and slowly titrated to a desirable effect, so that the adverse effects are minimal. If a side effect is very likely to occur and can trouble the patient, he/she should be properly counseled such that the side effect of the drug gets spotted in case it occurs.

\section{REFERENCES}

1. Rochon PA, Gurwitz JH. The prescribing cascade revisited [Internet]. Vol. 389, The Lancet. Lancet Publishing Group; 2017 [cited 2020 Jul 26]. p. 177880.

2. Kalisch LM, Caughey GE, Roughead EE, Gilbert AL. The prescribing cascade. Aust Prescr [Internet]. 2011 [cited $2020 \mathrm{Jul} 28$ ];34(6):162-6. [DOI]
What to do once new symptoms attributed to ADR is spotted?

1. Dose reduction of the linked drug, if the side effect is dose related

2. Deprescribing the drug altogether and reassessing the need of the drug

3. Choosing an alternative drug altogether, devoid of such ADR

4. Possibly, applying safer prescribing strategies for the aged like FORTA (Fit fOR The Aged). FORTA is an evidence based medicine practice approach, introduced by Wehling in $2009^{8}$. It labels drugs positive/negative by categorizing them into four groups, Category A (Absolutely), B (Beneficial), C (Careful) to $D\left(D^{\prime}{ }^{\prime} t\right)$, on the basis of identifying overtreatment, undertreatment or mistreatment of a disease.

Until such time that the physicians can have access to complete medical history of the patient and give due importance to medication history during consultations, the chances of prescription cascade happening is immense. The medication history itself should be complete including the prescription drugs, OTC medicines and herbal/natural health products. A complete medication history along with proper medication reconciliation can prevent physicians from adding medicines unnecessarily in the first place. Medication reconciliation being the process of creating the utmost detailed list of all the medications a patient is taking-including drug name (generics), dosage, dosage form, frequency and route; and comparing the list against physician's admission, transfer and/or discharge orders, so as to provide correct medicines to the patient at all transition points within the hospital". The "Brown Bag Review" of medicines by the pharmacists is considered a valuable tool of medication reconciliation ${ }^{10}$. Therefore, medication reconciliation coupled with prescribers considering new signs and symptoms in the patient as possible side effects of drugs could help keep the prescription cascade at bay.

3. Dagli RJ, Sharma A. Polypharmacy: a global risk factor for elderly people. J Int oral Heal JIOH [Internet]. 2014 [cited 2020 Jul 28];6(6):i-ii. [PubMed]

4. Shenoy P, Harugeri A. Elderly patients' participation in clinical trials. Perspect Clin Res [Internet]. 2015 [cited 2020 Jul 28];6(4):184. [PubMed]

5. Tatonetti NP, Ye PP, Daneshjou R, Altman RB. Datadriven prediction of drug effects and interactions. 
Sci Transl Med [Internet]. 2012 Mar 14 [cited 2020 Jul 28];4(125):125ra31. [PubMed]

6. Scottl, Hilmer S, Reeve E, al. et. Reducing inappropriate polypharmacy: the process of deprescribing. JAMA Intern Med. 2015;175:827-34. [DOI]

7. Centor RM. To be a great physician, you must understand the whole story [Internet]. Vol. 9, MedGenMed Medscape General Medicine. WebMD/ Medscape Health Network; 2007 [cited 2020 Jul 28]. p. 59. [PubMed]

8. Kuhn-Thiel AM, Weiß C, Wehling M. Consensus validation of the FORTA (Fit for the Aged) List: A clinical tool for increasing the appropriateness of pharmacotherapy in the elderly. Drugs and Aging [Internet]. 2014 Feb 19 [cited 2020 Jul 28];31(2):13140. [DOI]

9. Patel E, Pevnick JM, Kennelty KA. Pharmacists and medication reconciliation: a review of recent literature. Integr Pharm Res Pract [Internet]. 2019 Apr [cited 2020 Jul 28];Volume 8:39-45. [PubMed]

10. Weiss BD, Brega AG, LeBlanc WG, Mabachi NM, Barnard $\mathrm{J}$, Albright $\mathrm{K}$, et al. Improving the effectiveness of medication review: Guidance from the health literacy universal precautions toolkit. J Am Board Fam Med [Internet]. 2016 Jan 1 [cited 2020 Jul 28];29(1):18-23. [PubMed] 